\title{
Longitudinal Mental Health Impact Among Police Responders to the 9/1 1 Terrorist Attack
}

\author{
Rosemarie M. Bowler, PhD, MPH, ${ }^{1 *}$ Matthew Harris, MA, (PhD pending), ${ }^{2}$ Jiehui Li, MBBS, MSc, $^{3}$ \\ Vihra Gocheva, BA, ${ }^{1}$ Steven D. Stellman, ${ }^{2}{ }^{3,4}$ Katherine Wilson, MA, ${ }^{2}$ \\ Howard Alper, $\mathrm{PhD}, \mathrm{MS}^{5}$ Ralf Schwarzer, $\mathrm{PhD}^{6,7}$ and James E. Cone, ${ }^{6 D}, \mathrm{MPH}^{3}$
}

Background Among police responders enrolled in the World Trade Center Health Registry (WTCHR), Post-traumatic Stress Disorder (PTSD) was almost twice as prevalent among women as men 2-3 years after the 9/11 attacks.

Methods Police participants in the WTCHR Wave 1 survey 2-3 years after 9/11/01, were reassessed for probable PTSD at Wave 2, 5-6 years after 9/11/01, using PCL DSM-IV criteria.

Results Police participants in the Wave 2 survey included 2,527 men, 413 women. The prevalence of "Probable PTSD" was $7.8 \%$ at Wave 1 and $16.5 \%$ at Wave 2. Mean PCL scores increased from 25.1 to 29.9 for men and 28.6 to 32.2 for women. Prevalence of PTSD was higher for women than for men at Wave $1\left(\chi^{2}=10.882\right.$, $P=0.002)$, but not Wave $2\left(\chi^{2}=2.416, P=0.133\right)$. Other risk factors included losing one's job after $9 / 11$ and being disabled.

Conclusions Prevalence of probable PTSD among police doubled between 20032004 and 2006-2007. After the 2-year time span, the gender difference was no longer significant; prevalence of PTSD symptoms increased and there was a substantial amount of co-morbidity with other mental health problems. Further development of prevention and intervention strategies for police responders with symptoms of PTSD is needed. The observed upward trend in PCL scores over time in police officers with PCL scores less than 44, suggests that PTSD prevention and intervention strategies should be applied to all police affected by the 9/11 attacks, not limited just to those with PTSD symptoms. Am. J. Ind. Med. 55:297-312, 2012.

(C) 2011 Wiley Periodicals, Inc.

KEY WORDS: 9/11 disaster; post-traumatic stress disorder; DSM-IV; police; longitudinal study; mental health

\footnotetext{
1Department of Psychology, San Francisco State University, San Francisco, California

${ }^{2}$ Alliant International University, San Francisco, California

${ }^{3}$ World Trade Center Health Registry, Division of Epidemiology, New York City Department of Health and Mental Hygiene, New York, New York

${ }^{4}$ Department of Epidemiology, Mailman School of Public Health, Columbia University, New York, New York

${ }^{5}$ Office of Health Care Access and Improvement, New York City Department of Health and Mental Hygiene, New York, New York

${ }^{6}$ Department of Psychology, Freie Universität, Berlin, Germany

${ }^{7}$ Warsaw School of Social Sciences and Humanities, Warsaw, Poland

Contract grant sponsor: ATSDR/CDC to the New York City DOHMH; Contract grant number:U50/ATU272750;

Contract grant sponsor: National Institute for Occupational Safety and Health (NIOHS/CDC); Contract grant number: 1U500H009739-1.

Disclosure Statement: The authors' of this manuscript do not have any conflicts, financial, or personal gain from the publication of this manuscript. The authors' freedom to design, conduct, interpret, and publish research is not compromised by the funder and does not necessarily represent the views of the WTCHR and NYC Department of Health and Mental Hygiene.

${ }^{*}$ Correspondence to: Rosemarie M. Bowler, PhD, MPH, 8371 Kent Drive, El Cerrito,CA94530.E-mail: rbowl@ sfsu.edu
} 


\section{INTRODUCTION}

The terrorist attacks on the World Trade Center (WTC) on 9/11/01 caused nearly 2,800 immediate deaths and a substantial number of injuries [Galea et al., 2002; City of New York Bureau of Vital Statistics, 2003; Perlman et al., 2011]. Within minutes of the attack, police officers were among the first to arrive at the scene [Levenson and Acosta, 2001] and witnessed as people jumped from the burning and collapsing WTC towers. Police officers were instrumental in assisting survivors, guarding the perimeter of the WTC site and makeshift morgues, and participating in the unremitting search for bodies and body parts.

Numerous studies have been conducted on the prevalence of post-traumatic stress disorder (PTSD) within the first year after 9/11/01 and the reported prevalence varies widely among studies [CDC, 2002a, b; Galea et al., 2002; Schlenger et al., 2002; Silver et al., 2002; Lawyer et al., 2006]. A study of the first responders enrolled in the World Trade Center Health Registry (WTCHR) reported an overall probable PTSD prevalence 2-3 years post-9/11 of $15.4 \%$, with a range from $8.3 \%$ among police to $24.5 \%$ among unaffiliated volunteers [Perrin et al., 2007].

Within the same cohort, the prevalence of probable PTSD for the 4,014 police studied at baseline (2-3 years post-9/11) by the present authors was $8.3 \%$ [Bowler et al., 2010], which is double the US prevalence (3.6\%) [Department of Health and Human Services, 2010] reported in the early 1990s. For traumatized police officers prior to $9 / 11$, the prevalence of PTSD was 7\% within 12 months of experiencing a traumatic event, using DSMIII-R criteria [Carlier et al., 1997]. A higher prevalence of probable PTSD was found for women police responders in Wave 1 (13.9\% for women; $7.4 \%$ for men) [Bowler et al., 2010]. The finding of elevated prevalence levels of probable PTSD for women was consistent with studies of civilian populations, but differed from other studies of PTSD in rescue and recovery workers at the WTC, and police officers prior to 9/11/01 [Pole et al., 2001]. Some of the risk factors for police first responders of both genders identified by Bowler et al. [2010] were 9/11-related injury and older age (associated with the PCL domains of reexperiencing/intrusion and hypervigilance/hyperarousal). This study was the first to identify gender-specific risk factors among police responders following the WTC terror attack, identifying presence in WTC Towers on 9/11 and Hispanic ethnicity as risk factors for men, and identifying witnessing horror and education less than a college degree as risk factors specific to the women police.

Few studies have investigated post-9/11 PTSD prevalence longitudinally. The majority of published studies have reported diminishing levels of PTSD with the passage of time in cohorts of first responders to the WTC disaster [Galea et al., 2008; Stellman et al., 2008], although some have reported an increase in probable PTSD in a group of workers and in a group of firefighters [Brackbill et al., 2009b; Berninger et al., 2010a, b]. Berninger et al. [2010b] report that $8.6 \%$ of firefighters had probable PTSD at baseline, (within 6 months of 9/11), which increased to $11.1 \%$ at "postdisaster" follow-up (2.9 years). Nearly half of the firefighters had delayed onset of probable PTSD [Berninger et al., 2010b], defined as meeting probable PTSD criteria at follow-up but not at baseline. Given the consistently higher rates of probable PTSD within 3 or more years after $9 / 11$, Berninger et al. note that the nature of the work performed by rescue and recovery groups may have been differentially traumatic. Moreover, they found that difficulty in functioning at home or at work 3-4 years post-9/11 were strongly associated with a significant increase in probable PTSD [Berninger et al., 2010b].

Although there have been several follow-up studies of the prevalence of PTSD among firefighters (up to 3 years after 9/11) and the general population exposed to 9/11, there have been no published longitudinal studies (greater than 6 years) of police officers. Identification of policespecific risk factors for chronic and delayed-onset probable PTSD may help guide police departments and mental health professionals in establishing mental health treatment programs which may diminish the duration and delayed onset of PTSD in police officers. The identification of the major risk factors for developing delayed or chronic PTSD in police may facilitate police departments' immediate responses after a terrorist incident.

\section{METHODS}

The Registry's methods are described in detail elsewhere [Farfel et al., 2008; Brackbill et al., 2009b]. Briefly, potential enrollees were rescue/recovery workers and volunteers, lower Manhattan area residents, workers, school staff and attendees, and commuters and passersby on 9/11. Lists of potentially eligible persons were obtained from lower Manhattan area employers and government agencies (list-identified enrollees), and broad-based, multilingual media campaigns were used to encourage other potentially eligible persons (self-identified enrollees) to enroll via a Web site or toll-free telephone number. Between September 2003 and November 2004, 71,437 persons provided informed consent and completed a computer-assisted telephone $(94.5 \%)$ or in-person $(5.5 \%)$ enrollment interview regarding demographics, exposures incurred during and after the disaster, symptoms and medically diagnosed conditions (Wave 1). A Wave 2 follow-up study requested an update on registrants' symptoms, medically diagnosed conditions and social integration, referring to the structure and quantity of social relationships, such as the size and 
density of networks and the frequency of interaction. The Wave 2 study was conducted from November 2006 through December 2007 using two initial data collection modes: internet-based and via mail. In the last 3 months of data collection, non-participants were re-contacted to complete a computer-aided telephone interview. The Centers for Disease Control and Prevention (CDC) and New York City (NYC) Department of Health and Mental Hygiene (DOHMH) institutional review boards approved the Registry protocol.

\section{Study Population}

As described previously [Bowler et al., 2010], police responders to the $9 / 11$ terrorist attack and its aftermath were included if they had worked at least one shift from September 11, 2001, to June 30, 2002, at the WTC or related sites, or were involved in the transportation of the debris between the WTC site and barges, and completed the Wave 2 questionnaire. Excluded were those who did not answer all 17 PTSD Checklist (PCL) questions on either Wave 1 or 2, those without age or gender information, or who worked exclusively at the Staten Island Landfill; who were not asked the same exposure questions as the remainder of the group.

\section{Study Variables}

The primary mental health outcome for the present study was event-related post-traumatic stress symptoms indicative of probable PTSD. This was assessed with the stressor-specific PTSD Checklist (PCL), a 17-item selfreport instrument based on the Diagnostic and Statistical Manual of Mental Disorders (Fourth Edition) criteria [American Psychiatric Association, 1994] and linked to a specific traumatic exposure (i.e., "the events of September 11 "). To assess the potential for co-morbid and pre-existing mental health problems at the time of the Wave 1 assessment, participants were asked during the interview if they have had depression, anxiety, or other emotional problems since 9/11. If they answered affirmatively, they were asked if they had these before $9 / 11$ and whether these symptoms got worse after $9 / 11$. The Wave 2 assessment inquired whether they had ever been clinically diagnosed with anxiety, depression, or PTSD, and if so, whether this was pre- or post-9/11/01.

9/11-related exposure variables included the days of work at the WTC site, and number of traumatic events witnessed on 9/11. Several questions were asked about participants' degree of social integration during Wave 2. Using principal components analysis, two social integration factors were derived. The first, "friendship contacts," included items related to frequency of contact with friends and family members, and the second, "group involvement" related to frequency of attendance in group and community activities. Also included was the Kessler-6 [Kessler et al., 2002], a 6-item screen that is used to create a non-specific Psychological Distress Index (PDI).

Different trajectories of PTSD symptoms between the two time points were examined. Registrants' PTSD status was considered "Chronic" if they met "probable PTSD" criteria over both time points, "Recovered" if they met criteria at Wave 1 only, "Delayed" if they met criteria at Wave 2 only, and "Resilient" if they did not meet criteria at either wave. Resiliency is defined as a process of successful adaptation when victims persist in the face of critical life events and bounce back from adversity [Tedeschi and Calhoun, 1995; Bonanno, 2004; Bonanno et al., 2010]. Resilient individuals may still suffer from symptoms but they do not meet the cut-off for PTSD.

\section{Data Analysis}

SAS version 9.2 [SAS Institute Inc., 2008] and SPSS version 18.0 [SPSS Inc., 2009] were used to analyze data. Wave 2 participants were compared to non-participants on demographics, exposures, and health outcome responses, using $\chi^{2}$ tests. For all analyses, $P$-values involved hypothesis testing against a two-sided alternative and were considered significant at $P<0.05$. Psychological outcome measures were compared at Waves 1 and 2, separately for women and men, using $\chi^{2}$ and paired-samples $t$-tests.

The primary outcome, the individual registrant's PCL score at Waves 1 and 2, was obtained by summing the numeric value of the responses to each of the $17 \mathrm{PCL}$ items, ranging from 1, representing "Not at all", to 5, representing "Extremely." This total PCL score was the outcome measure used to examine how PTSD symptom levels changed with time from baseline (2003/2004), controlling for fixed effects, such as demographics, exposure type and level, and mental or physical health problems pre-9/11. In order to further explore the differences in PTSD symptomatology between men and women at both time points, we used Fisher's exact test to compare the prevalence of individuals meeting DSM-IV criteria for intrusion (1/5 items endorsed as "moderate" or greater), avoidance ( $3 / 7$ items), and hypervigilance ( $2 / 5$ items) from the PCL. Participants were determined to have "probable PTSD" if they endorsed items corresponding to DSM-IV criteria with a rating of "moderate" or higher: one or more intrusion items, 3 or more avoidance items, and 2 or more hypervigilance items.

Additionally, McNemar's test was used to compare categorical variables over time, and Wilcoxon Signed Rank Test was used for continuous variables. Analysis of Variance (ANOVA) analyses were used to compare mean scores for the PCL between groups. Non-parametric 
correlations (Spearman's $\rho$ ) were conducted regarding alcohol use and PCL scales at Wave 2, separately for women and men.

The PDI index was scored using the unweighted sum of responses, ranging from "none of the time," coded as zero, to "all of the time," coded as 4 . Thus the range of the total of each individual's responses was 0-24.

In order to compute the adjusted estimate of the PCL scores associated with 9/11-related exposures, social integration, losing their job or being disabled after $9 / 11$, and to capture the change of PCL scores between the 2 survey time points for women and men police, a random coefficient model was utilized. This model was computed using the Random statement in the SAS PROC MIXED command to model the within-subject correlation arising from the repeated measures obtained in Waves 1 and 2 and the correlation between subjects. An unstructured covariance matrix was used. We computed two-way interactions between year of testing and gender, mode of test administration, or other risk factors (e.g., unemployment or disability since 9/11). Estimates of effect were adjusted for age at 9/11, ethnicity, household income in 2002, survey mode, smoking and change in marital status. In the final model, injury as a result of the 9/11 attack, previously identified as one of the risk factors for probable PTSD in our first paper, and start date of work at WTC site, identified as a risk factor in previous studies [Perrin et al., 2007; Brackbill et al., 2009a; Berninger et al., 2010a, b], were not included, because these variables were highly correlated with the number of traumatic events witnessed on $9 / 11$.

\section{RESULTS}

\section{Response Rate and Attrition Analysis}

From the original 4,091 registrants who took part in the Wave 1 study, 1,042 (25.5\%) did not complete the Wave 2 questionnaire. Of the 3,049 who participated at Wave 2, a total of 109 did not provide complete data or did not complete all of the PCL items during both waves. This resulted in the final sample of 2,940 participants, most of whom were employed by the NYPD.

Those who responded in Wave 2 but did not complete the PCL at either Wave 1 or 2 were compared to those who did complete the PCL at both times (data not shown). Chi-square analyses revealed that respondents differed significantly from non-respondents in race/ethnicity $(P<0.001)$, income $(P<0.001)$, age $(P<0.001)$, education $(P<0.001)$, marital status $(P<0.001)$, and smoking frequency $(P<0.001)$. Non-respondents included a higher proportion of African Americans (13.5\%) compared with respondents $(6.4 \%)$; had a higher proportion of individuals with income less than $\$ 50,000$ (13.9\% vs. 9.0\%; $P<0.001)$, had age below $45(89.3 \%$ vs. $84.4 \%$; $P<0.001)$, education of 15 years or less $(63.6 \%$ vs. $61.3 \% ; P<0.001)$, and more were unmarried $(38.9 \%$ vs. $29.0 \% ; P<0.001)$. The respondents did not differ from non-respondents on Wave 1 PCL scores.

\section{Descriptive Analyses}

Demographic variables for those who responded at both Waves 1 and 2 are reported for the entire sample and separately by gender in Table I. A greater proportion of women than men had at least 18 years of education; selfidentified as Hispanic or African American; reported lower total household income in 2002; were unmarried, separated, or divorced at both time points; had no children; and smoked every day. Marital status changed significantly $(P<0.001)$, with more registrants being married $(75.0 \%)$ or divorced $(7.3 \%)$ at Wave 2 , compared to Wave 1 (70.9\% married, 6.4\% divorced). A lower proportion of registrants smoked at Wave $2(P<0.001)$ and more were unemployed (Wave 1: 8.5\%; Wave 2: 16.8\%; $P<0.001$ ).

\section{Change in PTSD Symptoms and Psychological Distress Over Time}

More registrants met the criteria for "probable PTSD" $(P<0.001)$ at Wave $2(\mathrm{~N}=485,16.5 \%)$ than at Wave $1(\mathrm{~N}=230,7.8 \%)$ for both men and women, and mean scores on the PCL increased significantly for both men (Wave 1: 25.1; Wave 2: 29.9; $P<0.001$ ) and women (Wave $1=28.6$; Wave $2=32.2$ ); $P<0.001$ ). Scores on each PCL subscale increased significantly $(P<0.001)$ from Waves 1 to 2 for both men and women (Table II). Additionally, $6.7 \%$ of the sample reported feeling emotionally numb or being unable to have loving feelings for those close to the registrant (PCL item \# 11) at Wave 1 , while $15.6 \%$ reported feeling emotionally numb at Wave 2, a significant increase $\left(\chi^{2}=403.562, P<0.001\right)$. Endorsement of emotional numbness did not differ by gender. Mean scores on the PDI increased significantly over time $(P<0.001)$ for both women (Wave 1: 3.5, Wave 2: 4.8) and men (Wave 1: 2.4, Wave 2: 4.1) (Table II).

Mean scores on the PCL at each time point for each of the PTSD trajectory groups (Resilient, Delayed, Chronic, and Recovered) are shown in Figure 1. The majority of the sample was considered Resilient ( $81 \%$ ), followed by Delayed (11.2\%), Chronic (5.3\%), and Recovered (2.5\%). Mean PCL scores for the Resilient and Chronic groups increased from Waves 1 to 2, the Delayed group's mean PCL scores increased by 21.2 and the Recovered group's PCL scores decreased by 9.9 . 
TABLE I. Sociodemographics of Study Sample by Gender ( $N=2,940)$

\begin{tabular}{|c|c|c|c|c|c|}
\hline & \multicolumn{2}{|c|}{ Women $(\mathbf{N}=\mathbf{4 1 3})$} & \multicolumn{2}{|c|}{$\operatorname{Men}(N=2,527)$} & \multirow[b]{2}{*}{$P$-value ${ }^{\text {a }}$} \\
\hline & N & $\%$ & N & $\%$ & \\
\hline \multicolumn{6}{|l|}{ Age group at 9/11 } \\
\hline $18-24$ & 13 & 3.1 & 50 & 2.0 & 0.128 \\
\hline $25-44$ & 343 & 83.1 & 2,078 & 82.2 & 0.686 \\
\hline $45-68$ & 57 & 13.8 & 399 & 15.8 & 0.301 \\
\hline \multicolumn{6}{|l|}{ Education reported at Wave 1 (in years) } \\
\hline $9-11$ & 4 & 1.0 & 12 & 0.5 & 0.208 \\
\hline 12 & 71 & 17.2 & 484 & 19.2 & 0.333 \\
\hline $13-15$ & 158 & 38.3 & 1,073 & 42.5 & 0.099 \\
\hline $16-17$ & 128 & 31.0 & 759 & 30.0 & 0.720 \\
\hline 18 or more & 51 & 12.3 & 186 & 7.4 & 0.001 \\
\hline \multicolumn{6}{|l|}{ Race/ethnicity } \\
\hline Non-Hispanic white & 221 & 53.5 & 1,954 & 77.3 & $<0.001$ \\
\hline Non-Hispanic black & 72 & 17.4 & 115 & 4.6 & $<0.001$ \\
\hline Hispanic & 103 & 24.9 & 345 & 13.7 & $<0.001$ \\
\hline Asian & 6 & 1.5 & 64 & 2.5 & 0.182 \\
\hline Multiracial & 9 & 2.2 & 27 & 1.1 & 0.057 \\
\hline Other ${ }^{\mathrm{b}}$ & 2 & 0.5 & 22 & 0.9 & 0.419 \\
\hline \multicolumn{6}{|l|}{ Total household gross income in 2002} \\
\hline$<\$ 25,000$ & 2 & 0.5 & 11 & 0.4 & 0.899 \\
\hline$\$ 25,000$ to $<\$ 50,000$ & 65 & 15.7 & 186 & 7.4 & $<0.001$ \\
\hline$\$ 50,000$ to $<\$ 75,000$ & 126 & 30.5 & 635 & 25.1 & 0.020 \\
\hline$\$ 75,000$ to $<\$ 100,000$ & 130 & 31.5 & 869 & 34.4 & 0.251 \\
\hline$\$ 100,000$ or more & 89 & 21.5 & 822 & 32.5 & $<0.001$ \\
\hline \multicolumn{6}{|l|}{ Marital status at Wave 2} \\
\hline Married & 174 & 43.0 & 2,010 & 80.1 & $<0.001$ \\
\hline Notmarried, but living with a partner & 58 & 14.3 & 89 & 3.6 & $<0.001$ \\
\hline Widowed & 6 & 1.5 & 3 & 0.1 & $<0.001$ \\
\hline Divorced & 63 & 15.6 & 151 & 6.0 & $<0.001$ \\
\hline Separated (notliving together) & 14 & 3.5 & 53 & 2.1 & 0.08 \\
\hline Never married & 90 & 22.2 & 202 & 8.1 & $<0.001$ \\
\hline \multicolumn{6}{|l|}{ Change in marital status } \\
\hline Remained married through Wave 2 & 169 & 40.9 & 1,786 & 70.7 & $<0.001$ \\
\hline Remained separated/divorced/never married & 109 & 26.4 & 248 & 9.8 & $<0.001$ \\
\hline Changed from married/living with partner to separated/divorced & 25 & 6.1 & 67 & 2.7 & $<0.001$ \\
\hline Allothers & 110 & 26.6 & 426 & 16.9 & $<0.001$ \\
\hline \multicolumn{6}{|l|}{ Smoking statusat Wave 2} \\
\hline Every day & 37 & 9.0 & 141 & 5.6 & 0.007 \\
\hline Some days & 24 & 5.8 & 128 & 5.1 & 0.515 \\
\hline Notatall & 350 & 85.2 & 2,255 & 89.2 & 0.013 \\
\hline \multicolumn{6}{|l|}{ Change in smoking status } \\
\hline Never & 225 & 54.5 & 1,630 & 64.5 & $<0.001$ \\
\hline BeforeWave1 only & 103 & 24.9 & 538 & 21.3 & 0.096 \\
\hline Wave1only & 22 & 5.3 & 90 & 3.6 & 0.082 \\
\hline Wave 2 only & 13 & 3.1 & 65 & 2.6 & 0.500 \\
\hline Waves1and 2 & 50 & 12.1 & 204 & 8.1 & 0.007 \\
\hline \multicolumn{6}{|l|}{ Change in employment } \\
\hline Wave1+Wave $2+$ & 306 & 74.1 & 2,040 & 80.7 & 0.004 \\
\hline
\end{tabular}


TABLE I. (Continued)

\begin{tabular}{|c|c|c|c|c|c|}
\hline & & & Mer & & \\
\hline & N & $\%$ & N & $\%$ & $P$-value ${ }^{\text {a }}$ \\
\hline Wave1+Wave2- & 70 & 16.9 & 274 & 10.8 & $<0.001$ \\
\hline Wave1-Wave $2+$ & 17 & 4.1 & 83 & 3.3 & 0.397 \\
\hline Wave1-Wave2- & 20 & 4.8 & 129 & 5.1 & 0.823 \\
\hline Currently disabled reported at Wave 2 & 17 & 4.1 & 106 & 4.2 & 0.942 \\
\hline Number of Childrenat Wave 2 & & & & & \\
\hline 0 & 213 & 51.6 & 861 & 34.1 & $<0.001$ \\
\hline 1or 2 & 163 & 39.5 & 1,236 & 48.9 & $<0.001$ \\
\hline 3 or more & 33 & 8.0 & 408 & 16.1 & $<0.001$ \\
\hline Survey (Wave 2) mode & & & & & \\
\hline Phone & 45 & 10.9 & 254 & 10.1 & 0.599 \\
\hline Mail or Web & 368 & 89.1 & 2,273 & 89.9 & \\
\hline
\end{tabular}

aIncludes American Indian, Alaskan Native, and unknown.

${ }^{\mathrm{b}}$ Pearson's chi-square test.

\section{Gender Differences in PTSD and Psychological Distress}

The prevalence of meeting "probable PTSD" criteria was significantly higher for women than for men (Table II) at Wave $1\left(11.9 \%\right.$ vs. $\left.7.2 \%, \chi^{2}=10.882, P=0.002\right)$ but not at Wave $2\left(19.1 \%\right.$ vs. $\left.16.1 \%, \chi^{2}=2.416, P=0.133\right)$.

Significantly more women than men met criteria for intrusion at Wave $1\left(34.6 \%\right.$ vs. $25.3 \%, \chi^{2}=15.854$, $P<0.001)$ and Wave $2\left(45.8 \%\right.$ vs. $38.2 \%, \chi^{2}=8.543$, $P=0.004)$, and significantly more women met criteria for hypervigilance $\left(31.5 \%\right.$ vs. $21.1 \%, \quad \chi^{2}=22.110$, $P<0.001)$ and avoidance $\left(15.0 \%\right.$ vs. $10.6 \%, \chi^{2}=6.918$, $P=0.011)$ at Wave 1 only.
On all three PCL subscales, women scored significantly higher than men at both time points, but men consistently showed a larger increase over time than women. Mixed model ANOVAs revealed interaction effects between gender and time point, indicating that men increased significantly more over time than women on PCL Total scores $(F(\mathrm{df}=1, \mathrm{~N}=2938)=243.96, P<0.001)$, intrusion $(F(\mathrm{df}=1, \quad \mathrm{~N}=2938)=133.40, \quad P<0.001)$, hypervigilance $(F(\mathrm{df}=1, \mathrm{~N}=2938)=160.03, P<0.001)$, and avoidance $(F(\mathrm{df}=1, \mathrm{~N}=2938)=238.25, P<0.001)$. Women obtained significantly higher mean PDI scores than men at Wave 1 (3.5 vs. $2.3, P<0.001)$ and Wave 2 (4.8 vs. $4.1, P=0.002$ ), though the gender difference was greater at Wave 1 .

TABLE II. Probable PTSD (Using DSM-IV) and PCL and PDI Scores by Gender and Time of Study

\begin{tabular}{|c|c|c|c|c|c|c|c|c|c|c|}
\hline & \multicolumn{5}{|c|}{ Women $(N=413)$} & \multicolumn{5}{|c|}{$\operatorname{Men}(N=2,527)$} \\
\hline & \multicolumn{2}{|c|}{ Wave1 } & \multicolumn{2}{|c|}{ Wave 2} & \multirow[b]{2}{*}{$P$-value ${ }^{\text {a }}$} & \multicolumn{2}{|c|}{ Wave1 } & \multicolumn{2}{|c|}{ Wave 2} & \multirow[b]{2}{*}{$\boldsymbol{P}$-value } \\
\hline & $\begin{array}{c}\text { Number and } \\
\text { prevalence of } \\
\text { probable PTSD }\end{array}$ & $\begin{array}{c}\text { Mean } \\
\text { (SD) }\end{array}$ & $\begin{array}{l}\text { Number and } \\
\text { prevalence of } \\
\text { probable PTSD }\end{array}$ & $\begin{array}{c}\text { Mean } \\
\text { (SD) }\end{array}$ & & $\begin{array}{c}\text { Number and } \\
\text { prevalence of } \\
\text { probable PTSD }\end{array}$ & $\begin{array}{c}\text { Mean } \\
\text { (SD) }\end{array}$ & $\begin{array}{c}\text { Number \& } \\
\text { prevalence of } \\
\text { probable PTSD }\end{array}$ & $\begin{array}{c}\text { Mean } \\
\text { (SD) }\end{array}$ & \\
\hline PCL total score & $49(11.9 \%)$ & $28.6(11.7)$ & $79(19.1 \%)$ & $32.1(14.6)$ & $<0.001$ & $181(7.2 \%)$ & $25.1(9.5)$ & $406(16.1 \%)$ & $29.9(13.4)$ & $<0.001$ \\
\hline Intrusion & $143(34.6 \%)$ & $8.3(3.5)$ & $189(45.8 \%)$ & $9.1(4.1)$ & $<0.001$ & $639(25.3 \%)$ & $7.2(2.7)$ & $965(38.2 \%)$ & $8.4(3.9)$ & $<0.001$ \\
\hline Avoidance & $62(15 \%)$ & $10.9(4.9)$ & $104(25.2 \%)$ & $12.7(6.5)$ & $<0.001$ & $268(10.6 \%)$ & $9.6(4.1)$ & $538(21.3 \%)$ & $11.7(5.7)$ & $<0.001$ \\
\hline Hypervigilance & $130(31.5 \%)$ & $9.4(4.5)$ & $164(39.7 \%)$ & $10.5(5.3)$ & $<0.001$ & $532(21.1 \%)$ & $8.2(3.7)$ & $886(35.1 \%)$ & $9.8(4.9)$ & $<0.001$ \\
\hline $\begin{array}{l}\text { Psychological } \\
\text { Distress Index }\end{array}$ & - & $3.5(4.0)$ & - & $4.8(5.0)$ & $<0.001$ & - & $2.3(3.3)$ & - & $4.1(4.6)$ & $<0.001$ \\
\hline
\end{tabular}

WWilcoxon signed-rank test, within gender. 


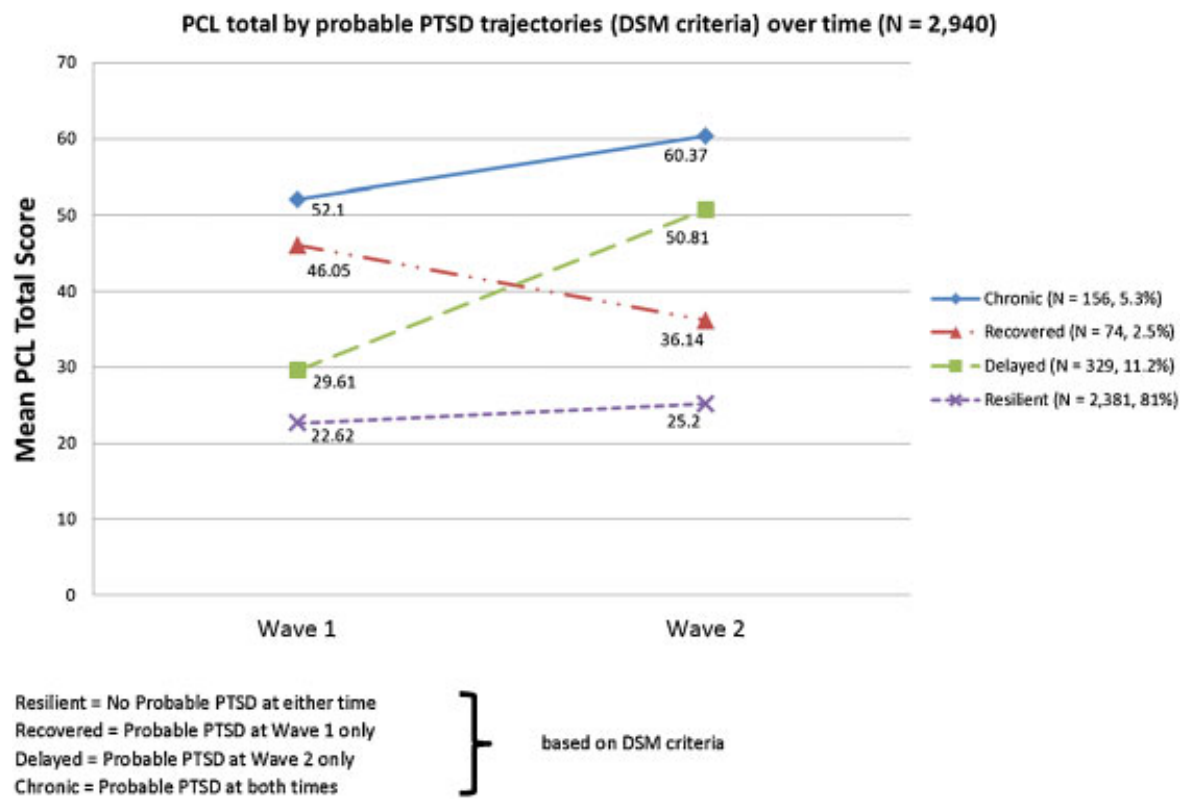

FIGURE 1. Trajectories of PCL among police responders, Waves 1 to 2 studies by probable PTSD category. [Color figure can be seen in the online version of this article, available at http://wileyonlinelibrary.com/journal/ajim]

\section{Mental Health Diagnoses}

Mental health diagnoses of PTSD, anxiety disorders, or depression by a mental health professional are presented by gender in Table III. Each of these mental health diagnosis variables were significantly associated with PCL scores $(P<0.001)$ for both men and women. Additionally, seeing a mental health professional and taking psychiatric medication were related to higher PCL scores. Consistent with gender differences on the PCL, significantly more women than men $(P<0.001)$ reported diagnoses of anxiety, depression, or PTSD, were currently taking psychiatric medications, or were seeing a mental health professional. For both women and men who had PTSD, depression, or anxiety diagnoses, PCL scores were higher for those with a more recent diagnosis (diagnosed between $9 / 11$ and Wave 1 or between Waves 1 and 2) than those who were diagnosed before 9/11. The percentages of police registrants diagnosed with specific mental health conditions were: $9.9 \%$ PTSD, $10.5 \%$ depression and 6.9\% anxiety (Fig. 2). The overlap between medical or mental health provider-diagnosed PTSD, depression, and anxiety is shown in Figure 2. The largest areas of overlap were between depression and PTSD (3.3\%), and depression, anxiety and PTSD (3.2\%).

\section{Risk Factors}

Table IV shows the multivariate analysis results of the basic model (which included age, gender, and time point) and the final model (which included age, gender, Hispanic ethnicity, household income, response mode, days of work at WTC, number of traumatic events witnessed on 9/11, smoking status, losing job after $9 / 11$, being currently disabled, change in marital status, social integration, and time point, but not race) with the PCL scores. The intercept variance decreased greatly from 37.3 in the basic model to 17.9 in the final model, which indicates that about $52 \%$ of the explainable variation in their mean PCL scores is accounted for by additional variables added in the final model. The final model highlights several variables that were significantly related to PCL scores. These include female gender, older age on $9 / 11$, responding to the study by phone, witnessing more traumatic events on $9 / 11$, being a current smoker, having lost one's job after 9/11, and having lower levels of social integration. "Days of work at the WTC" was not significant in the final model. Additionally, significant interaction effects were found between time and gender, method of response to the study, employment status, and disability status, indicating that each predictor is associated with differences in the change in PCL scores over time. Factors that were related to a greater increase in PCL scores over time were male gender, responding to the study by mail or web, having lost their job after $9 / 11$, and being disabled. Both the basic and final models are displayed in Figure 3A,B. After adjusting for covariates, the increase in PCL score among men is greater than among women police officers over time.

Frequency of alcohol use per month by gender at the Wave 2 assessment showed a significant difference $\left(\chi^{2}=20.722, P<0.001\right)$, indicating that men drank alcohol more often $(\leq 4$ drinks: $52.3 \% ;>4, \leq 30$ drinks: 
TABLE III. PCL scores at Wave 2 by Depression, Anxiety, and PTSD Diagnoses, and Mental Health Practices, by Gender

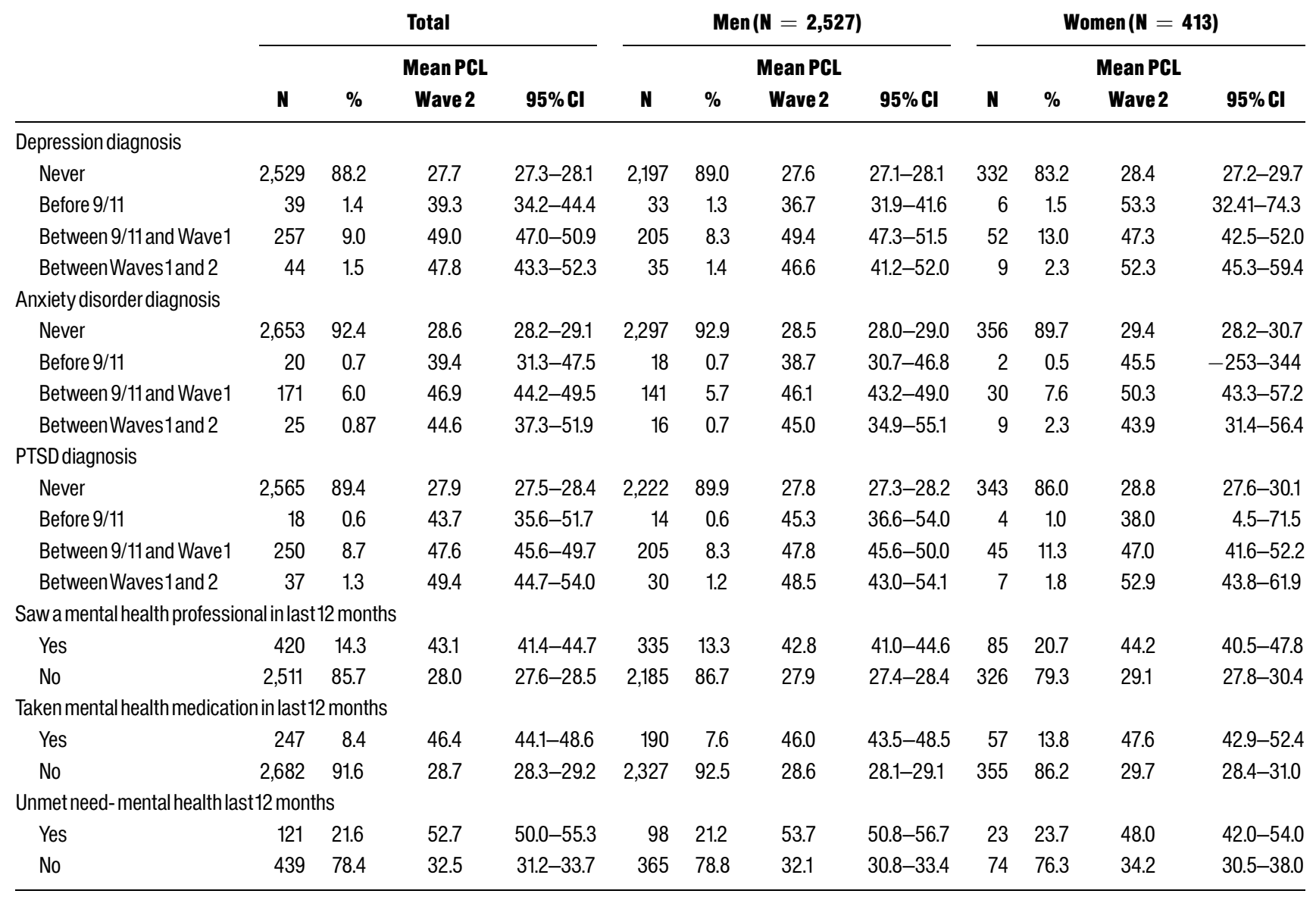

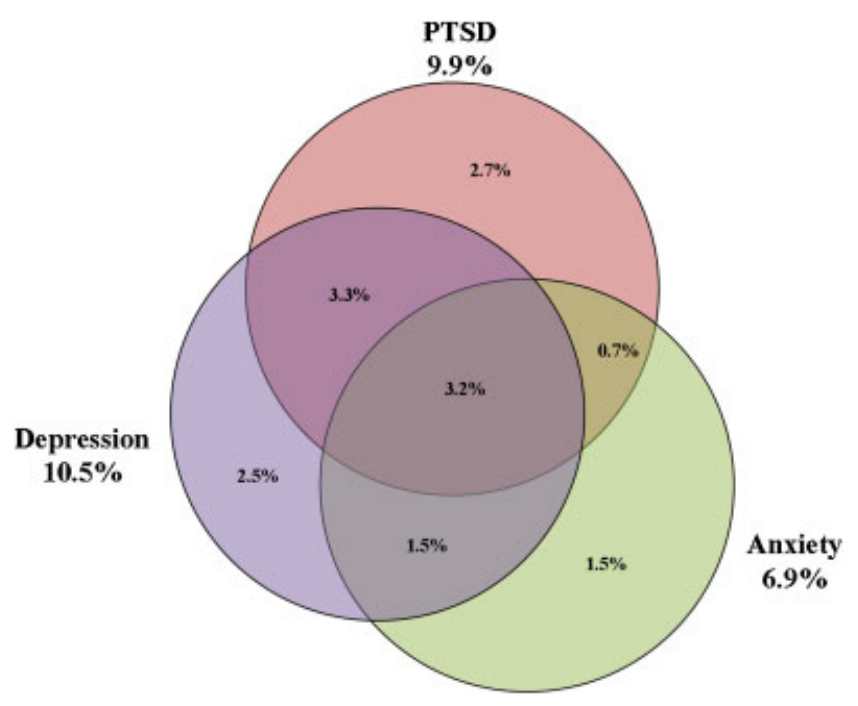

FIGURE 2. Total physician-diagnosed mental health conditions at Wave 2. [Color figure can be seen in the online version of this article, available at http://wileyonlinelibrary. com/journal/ajim]
36.4\%; $>30$ drinks: $11.3 \%$ ) than women ( $\leq 4$ drinks: $64.8 \%$; $>4, \leq 30$ drinks: $30.3 \%$; $>30$ drinks: $4.9 \%$ ). For men, greater alcohol use was related to higher total PCL scores at Wave 2 (Spearman's $\rho=0.092, P<0.001$ ), intrusion scores $(\rho=0.066, P=0.005)$, avoidance scores $(\rho=0.092, \quad P<0.001), \quad$ and hypervigilance scores $(\rho=0.082, \quad P<0.001)$. For women, greater alcohol use was related to higher total PCL scores $(\rho=0.120$, $P=0.030)$ and hypervigilance scores $(\rho=0.139, P=$ $0.015)$, but not to intrusion or avoidance scores, although the magnitude of the correlation coefficients were larger for each correlation in women than in men, suggesting that alcohol shows a stronger relationship with PCL scores in women than in men. However, alcohol use was not included in the multivariate analysis, because (1) information on alcohol use was unavailable for Wave 1, which did not allow the determination whether alcohol use was related to increased PCL scores, and (2) because PTSD and alcohol problems often occur together, which does not permit the differentiation of whether alcohol use is the cause or consequence of PTSD. 
TABLE IV. Multivariate Analysis of Change in PCL Score in Relation to Potential Risk Factors $(\mathrm{N}=2,940)$

\begin{tabular}{|c|c|c|c|c|c|c|c|c|c|c|c|}
\hline & & & & & & & Basic mode & & & Final model $^{\mathrm{a}}$ & \\
\hline & $\mathbf{N}$ & $\begin{array}{c}\text { \% PTSD } \\
\text { (PCL } \geq 44) \\
\text { atWave } 2\end{array}$ & $\begin{array}{c}\text { (DSM } \\
\text { criteria) } \\
\text { atWave } 2\end{array}$ & $\begin{array}{c}\text { score } \\
\text { at Wave } \\
1 \text { (SD) }\end{array}$ & $\begin{array}{c}\text { score } \\
\text { at Wave } \\
2 \text { (SD) }\end{array}$ & $\begin{array}{c}\text { Adjusted } \\
\beta\end{array}$ & $\begin{array}{l}\text { Adjusted } \\
\text { SE }\end{array}$ & $P$-value & $\begin{array}{c}\text { Adjusted } \\
\beta\end{array}$ & $\begin{array}{l}\text { Adjusted } \\
\text { SE }\end{array}$ & $P$-value \\
\hline Age at $9 / 11$ (year) $^{b}$ & & & & & & & & & & & \\
\hline $18-24$ & 63 & 14.3 & 15.9 & $24.2(8.9)$ & $29.9(14.3)$ & 0.12 & 0.03 & $<0.001$ & 0.07 & 0.03 & 0.035 \\
\hline $25-44$ & 2,421 & 15.0 & 16.1 & $25.4(9.6)$ & $30.0(13.2)$ & & & & & & \\
\hline $45-68$ & 456 & 19.5 & 18.9 & $26.8(11.4)$ & $31.6(15.2)$ & & & & & & \\
\hline Gender & & & & & & & & & & & \\
\hline Women & 413 & 19.6 & 19.1 & $28.6(11.7)$ & $32.2(14.6)$ & 4.78 & 0.78 & $<0.001$ & 5.37 & 1.08 & $<0.001$ \\
\hline Men & 2,527 & 15.1 & 16.1 & $25.1(9.5)$ & $29.9(13.4)$ & & & & Referent & & \\
\hline Ethnicity & & & & & & & & & & & \\
\hline Hispanic & 448 & 17.4 & 18.3 & $26.9(10.5)$ & $30.7(13.6)$ & & & & 1.1 & 0.65 & 0.092 \\
\hline Non-Hispanic & 2,492 & 15.4 & 16.2 & $25.3(9.8)$ & $30.1(13.6)$ & & & & Referent & & \\
\hline Total household income in 2002 & & & & & & & & & & & \\
\hline$<25,000$ & 13 & 38.5 & 30.8 & $36.7(21.8)$ & $39.9(20.5)$ & & & & -0.31 & 0.25 & 0.211 \\
\hline$\$ 25,000$ to $<\$ 50,000$ & 251 & 14.3 & 14.3 & $26.8(11.3)$ & $29.3(13.4)$ & & & & & & \\
\hline$\$ 50,000$ to $<\$ 75,000$ & 761 & 16.6 & 18.0 & $25.5(9.8)$ & $30.6(13.8)$ & & & & & & \\
\hline$\$ 75,000$ to $<\$ 100,000$ & 999 & 14.9 & 16.1 & $25.7(9.5)$ & $30.1(13.3)$ & & & & & & \\
\hline$\$ 100,000$ or more & 911 & 15.8 & 16.0 & $24.9(9.6)$ & $30.1(13.5)$ & & & & & & \\
\hline Responsemode & & & & & & & & & & & \\
\hline Phone & 299 & 12.7 & 12.7 & $26.0(10.3)$ & $27.6(13.0)$ & & & & 8.33 & 2.66 & 0.002 \\
\hline Mail or Web & 2,641 & 16.1 & 16.9 & $25.5(9.9)$ & $30.5(13.6)$ & & & & Referent & & \\
\hline Days of work at the WTC site & & & & & & & & & & & \\
\hline $1-7$ days & 611 & 14.4 & 15.1 & $25.7(10.4)$ & $29.9(13.6)$ & & & & 0.22 & 0.22 & 0.319 \\
\hline $8-30$ days & 914 & 16.0 & 16.7 & $25.4(10.3)$ & $30.1(13.6)$ & & & & & & \\
\hline $31-90$ days & 737 & 15.5 & 17.0 & $24.8(8.9)$ & $29.8(13.7)$ & & & & & & \\
\hline$>90$ days & 522 & 17.4 & 17.1 & $26.8(10.1)$ & $31.5(13.5)$ & & & & & & \\
\hline $\begin{array}{l}\text { Number of traumatic events } \\
\text { witnessed on } 9 / 11\end{array}$ & & & & & & & & & & & \\
\hline None & 1,098 & 10.4 & 11.4 & $23.7(8.8)$ & $27.7(12.1)$ & & & & 2.17 & 0.27 & $<0.001$ \\
\hline $1-2$ & 910 & 13.5 & 15.0 & $24.8(8.4)$ & $29.6(12.6)$ & & & & & & \\
\hline$\geq 3$ & 932 & 24.1 & 24.0 & $28.5(11.6)$ & $33.8(15.3)$ & & & & & & \\
\hline Smoking status & & & & & & & & & & & \\
\hline $\begin{array}{l}\text { Never (reported from } \\
\text { Waves1and 2) }\end{array}$ & 1,855 & 13.6 & 14.4 & $25.1(9.5)$ & $29.3(12.9)$ & & & & Referent & & \\
\hline Former (reported in Wave1) & 641 & 16.7 & 18.4 & $25.4(10.1)$ & $30.7(13.7)$ & & & & -0.60 & 0.56 & 0.283 \\
\hline $\begin{array}{l}\text { Current smoker (current } \\
\text { smoking in } \\
\text { W1and/or Wave 2) }\end{array}$ & 444 & 23.0 & 22.5 & $27.6(10.9)$ & $33.3(15.7)$ & & & & 1.91 & 0.63 & 0.002 \\
\hline Lostjob after $9 / 11$ & & & & & & & & & & & \\
\hline Yes & 153 & 52.9 & 52.9 & $36.7(15.6)$ & $46.9(19.9)$ & & & & 4.45 & 1.74 & 0.011 \\
\hline No & 2,772 & 13.6 & 14.5 & $24.9(9.1)$ & $29.3(12.5)$ & & & & Referent & & \\
\hline Currently disabled & & & & & & & & & & & \\
\hline Yes & 123 & 55.3 & 54.5 & $36.1(15.7)$ & $47.2(18.0)$ & & & & 3.11 & 1.76 & 0.078 \\
\hline No & 2,806 & 14.0 & 14.9 & $25.1(9.3)$ & $29.5(12.9)$ & & & & Referent & & \\
\hline Change in marital status & & & & & & & & & & & \\
\hline $\begin{array}{l}\text { Remained married } \\
\text { throughWave } 2\end{array}$ & 1,955 & 15.2 & 16.5 & $25.2(9.7)$ & $29.9(13.6)$ & & & & Referent & & \\
\hline
\end{tabular}


TABLE IV. (Continued)

\begin{tabular}{|c|c|c|c|c|c|c|c|c|c|c|c|}
\hline & \multirow[b]{2}{*}{$\mathbf{N}$} & \multirow[b]{2}{*}{$\begin{array}{c}\text { \% PTSD } \\
\text { (PCL } \geq 44) \\
\text { atWave } 2\end{array}$} & \multirow{2}{*}{$\begin{array}{c}\text { \% PTSD } \\
\text { (DSM } \\
\text { criteria) } \\
\text { at Wave } 2\end{array}$} & \multirow{2}{*}{$\begin{array}{c}\text { Mean } \\
\text { PCL } \\
\text { score } \\
\text { at Wave } \\
\text { 1(SD) }\end{array}$} & \multirow{2}{*}{$\begin{array}{c}\text { Mean } \\
\text { PCL } \\
\text { score } \\
\text { at Wave } \\
\text { 2(SD) }\end{array}$} & \multicolumn{3}{|c|}{ Basic model } & \multicolumn{3}{|c|}{ Final model $^{\mathbf{a}}$} \\
\hline & & & & & & $\begin{array}{c}\text { Adjusted } \\
\beta\end{array}$ & $\begin{array}{l}\text { Adjusted } \\
\text { SE }\end{array}$ & $P$-value & $\begin{array}{c}\text { Adjusted } \\
\qquad \beta\end{array}$ & $\begin{array}{l}\text { Adjusted } \\
\text { SE }\end{array}$ & $P$-value \\
\hline $\begin{array}{l}\text { Remained separated/ } \\
\text { divorced/never married }\end{array}$ & 357 & 14.6 & 15.7 & $26.3(10.2)$ & $30.4(12.8)$ & & & & 0.95 & 0.75 & 0.209 \\
\hline $\begin{array}{l}\text { Changed from married/living } \\
\text { with partner to separated/ } \\
\text { divorced }\end{array}$ & 92 & 21.7 & 18.5 & $27.6(12.1)$ & $32.6(14.6)$ & & & & 2.51 & 1.25 & 0.044 \\
\hline All others & 536 & 17.4 & 16.6 & $25.9(9.9)$ & $30.8(13.9)$ & & & & 0.09 & 0.67 & 0.894 \\
\hline \multicolumn{12}{|l|}{ Social integration ${ }^{c}$} \\
\hline Friendship contacts & & & & & & & & & -2.28 & 0.23 & $<0.001$ \\
\hline Group involvement & & & & & & & & & -0.47 & 0.24 & 0.051 \\
\hline Time point & & & & & & 1.72 & 0.08 & $<0.001$ & 1.95 & 0.11 & $<0.001$ \\
\hline $\begin{array}{r}\text { Time point by gender } \\
\text { (interaction term) }\end{array}$ & & & & & & -0.49 & 0.20 & 0.015 & -0.91 & 0.27 & 0.009 \\
\hline $\begin{array}{l}\text { Time point by response mode } \\
\text { (interaction term) }\end{array}$ & & & & & & & & & -1.33 & 0.63 & 0.036 \\
\hline $\begin{array}{r}\text { Time point by lostjob } \\
\text { (interaction term) }\end{array}$ & & & & & & & & & 1.76 & 0.45 & $<0.001$ \\
\hline $\begin{array}{l}\text { Time point by disabled } \\
\text { (interaction term) }\end{array}$ & & & & & & & & & 1.44 & 0.46 & 0.002 \\
\hline Intercept & & & & & & 16.13 & 1.00 & $<0.001$ & 13.64 & 1.69 & $<0.001$ \\
\hline
\end{tabular}

aIncluded all variables listed in this table, adjusting for time point. Dependent variable is mean PCL score.

bused as continuous in the model.

${ }^{\mathrm{C} U s i n g}$ Principal Component Analysis, 9 questions related to social integration were regrouped into two factors.

\section{DISCUSSION}

The present findings contribute to the body of research on the 9/11 aftermath and on mental health and coping with disasters in general. In their comprehensive reviews, Bonanno et al. [2010] and Norris et al. [2002] weigh the costs of disasters in terms of consequences, risks, and resilience. They state that (a) disasters cause
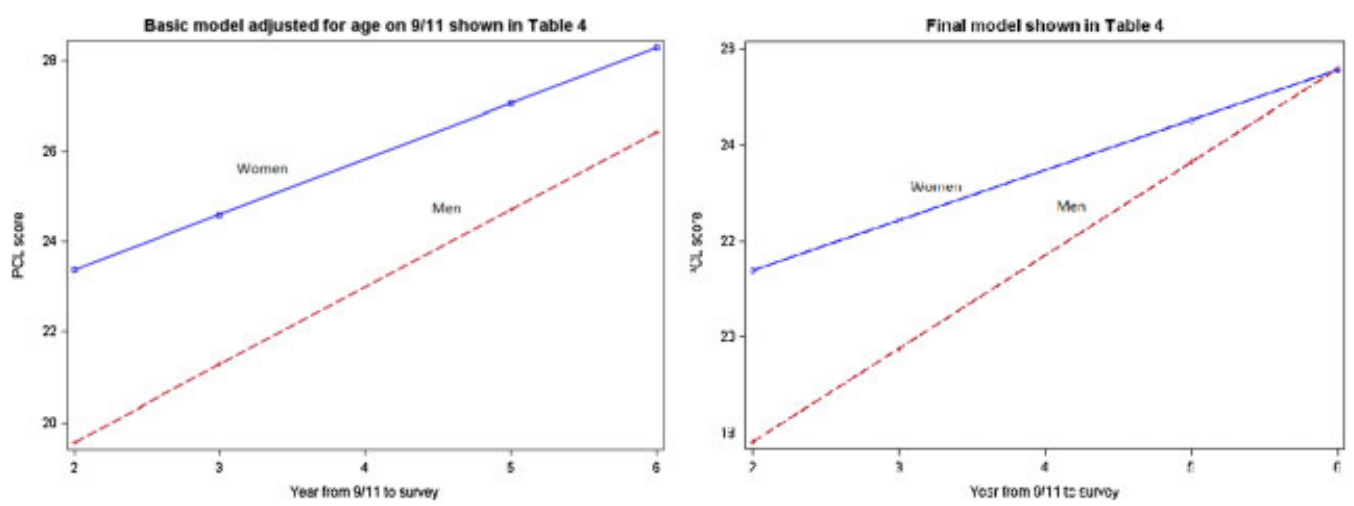

FIGURE 3. Multivariate analysis of change in PCL score in relation to potential risk factors: (A) basic model including age, gender, and time point and (B) final model including age, gender, ethnicity, household income, response mode, days of work at the World Trade Center, number of traumatic events witnessed on $9 / 11$, smoking status, losing job on $9 / 11$, being currently disabled, change in marital status, social integration, and time point. [Color figure can be seen in the online version of this article, available at http://wileyonlinelibrary. com/journal/ajim] 
serious psychological harm in a minority of exposed survivors, (b) disasters produce multiple patterns of outcome, including psychological resilience, and (c) disaster outcome depends on a combination or risk and resilience factors. People exposed to major life events may evidence depression, anxiety, illness symptoms, PTSD, or behavioral consequences such as substance use. Severe levels of such problems rarely occur in more than one third of exposed victims. Moreover, multiple longitudinal patterns of outcome have been observed. Authors have observed stability and change of symptoms over time that can be categorized into four groups labeled chronicity, delayed, recovery, and resilience. For example, in a study by Bonanno et al. [2005] on patterns of outcome among high-exposure survivors of the $9 / 11$ terrorist attack in New York, they found chronic levels of severe symptoms (PTSD and/or depression) in 29\% of this highly exposed sample (chronicity). In a further subsample of $13 \%$, similar levels were attained later on (delayed), whereas in $23 \%$, the initial symptoms were transient and had disappeared after 2 years (recovery). Finally, in 35\%, no major symptomatology was observed over the entire 2-year observation period (resilience). Many experienced only transient stress, or they maintained a stable trajectory of normal functioning, which means that those who are resilient plus those who recover within a 2 -year period after the event constitute the majority of the sample of exposed survivors [Bonanno et al., 2006].

Police responders, particularly men, have experienced increasing rates of probable PTSD over time. Type of disaster has been shown to have a major impact on sequelae [Norris et al., 2002; U.S. Department of Veterans Affairs, 2010], with severe levels of impairment most likely to occur in populations that experienced mass violence. Consistent with this observation, first responders to $9 / 11$, have shown an extraordinary high level of PTSD shortly after the terrorist attack occurred [CDC, 2002a]. During the follow-up of the police responding to the 9/11 attack, the overall proportion of registrants with probable PTSD doubled in the current study from $7.8 \%$ at Wave 1 to $16.5 \%$ at Wave 2, using the DSM-IV criteria on the PCL. This observed increase in PTSD symptoms over time postdisaster is highly unusual. In the Norris review [2002] only one of the 34 longitudinal studies reviewed showed an increase in symptoms over time.

This increased prevalence of probable PTSD was, however, found in both men $(7.2-16.1 \%)$ and women $(11.9-19.1 \%)$. However, in the Wave 2 study of WTCHR police registrants, women no longer had a statistically significantly greater prevalence of probable PTSD than men. The prevalence of those who met DSM-IV criteria on all three PCL subscales increased: intrusion increased for men from $25.3 \%$ to $38.2 \%$ and for women from $34.6 \%$ to $45.8 \%$; avoidance increased for men from $10.6 \%$ to $21.3 \%$ and for women from $15 \%$ to $25.2 \%$; hypervigilance increased for men from $21.1 \%$ to $35.1 \%$ and for women from $31.5 \%$ to $39.7 \%$. As shown in Figure 1, the majority $(81 \%)$ of the sample at Wave 2 did not meet criteria for probable PTSD at either point in time, and were considered resilient, $11.2 \%$ of the sample had delayed onset of probable PTSD (Wave 2 only), 5.3\% had chronic probable PTSD (both time points), and $2.5 \%$ were recovered and no longer met criteria for probable PTSD. It can be noted the "Recovered" group's mean PCL score was only 8 points below the cut-off of 44 , which is notable because the "Recovered" group is a mixed group of persons who are subclinical at Wave 2 and persons with a very low PCL score, who screen normal.

The prevalence among police of the "resilient" group is larger than the prevalence of "resilience" in residents of NYC who experienced 9/11, as reported by Bonanno et al. [2010]. In characterizing those who are "resilient," Bonanno et al. [2010], reported that only $65 \%$ of the NYC residents met criteria for "resilient" although among the police in the current study a much higher proportion, $81.0 \%$ meet the criteria for "resilient." This supports the hypothesis that police, who "are carefully screened and selected for both good psychological and physical health" may be expected to have lower prevalence of PTSD over time.

When examining the police registrants who did not participate in the Wave 2 study it is shown that they were younger, had lower income and less education, fewer were married, and more were African-Americans than the police registrants who responded to the Wave 2 study.

\section{Gender Differences in PCL Scores and DSM-IV Probable PTSD}

Women had higher total PCL scores than men at both time points, but men showed a proportionally larger increase of probable PTSD from Waves 1 to 2 than did women. The difference between men and women on PTSD was no longer significant at Wave 2. This suggests that planning for prevention of and relevant treatment for those police who have late onset of PTSD should focus on both men and women equally. As more women than men met DSM-IV criteria of intrusion at Waves 1 and 2 this should be addressed with specific treatment modalities.

\section{Risk Factors}

Unlike many previous studies of PTSD among rescue/ recovery workers, this study used the PCL scores that were surveyed at two time points as continuous variables and examined whether the increased PCL scores over time were associated with 9/11-related exposure. This study 
revealed that higher PCL scores (not just for those with probable PTSD) were not only associated with witnessing more traumatic events on $9 / 11$, but also with less social integration, having lost their job after $9 / 11$ and being disabled. More importantly, this study revealed that those who had PCL scores less than 44 also showed an upward trend over time, suggesting the prevention and intervention of PTSD should be applicable to all police affected by the 9/11 attacks, not limited only to those with PTSD symptoms.

Longitudinal examinations of risk factors for PTSD following the 9/11 events have been reported in several general population studies, but none focused specifically on police responders. In a group of New York residents assessed within 1-2 years after the WTC attack, Adams and Boscarino [2006] found that being middle-aged, being Latino, having experienced negative life events and traumas since 9/11, and having had lower self-esteem were significant risk factors for continuation of PTSD at followup. Similar to studies of the WTC rescue and recovery workers, exposure to WTC events was a risk factor for meeting PTSD criteria in the general population, but only at the baseline interviews [Adams and Boscarino, 2006]. Additionally, among another general population sample of 2,752 New York residents exposed to the 9/11 events, risk factors for PTSD over time included ongoing stressors and traumas, lack of strong social support, being a woman, and of Hispanic ethnicity.

Among ironworkers performing rescue and recovery work after 9/11, significant baseline risk factors for developing PTSD in rescue and recovery workers include alcohol misuse, injury to or death of a family member, friend or co-worker, or one or more adverse life events after 9/11 [Weissman et al., 2005; Katz et al., 2009]. Weissman et al. [2005] discuss gender differences in PTSD for women, but in their study of primary care patients, these differences were accounted for by differences in marital status and education. Galea et al. [2004] report increased PTSD in Hispanics being one of the most important risk factors from a survey of the NYC metropolitan residents.

Shortly after 9/11/01, Vlahov et al. [2002], in a random digit telephone dialing survey, reported a $24.6 \%$ increase in alcohol use in area residents. In another study of residents of New York City at the time of 9/11, Adams et al. [2006] found increased alcohol use to be related to PTSD 2 years after 9/11. Katz et al. [2009] found high rates of alcohol use among alcohol-consuming 9/11 male ironworkers and excessive alcohol consumption following the 9/11 events, which was associated with elevated PCL scores. In the present study, men drank alcohol more often than women, but alcohol use was more strongly related to higher PCL scores in women than men. This suggests that although men drink more, typically, alcohol use among women may be more indicative of a stress reaction or coping technique. As stated above, alcohol consumption could not be included in our longitudinal model because amounts of alcohol consumed were not available for Wave 1.

Risk factors for PTSD in police officers in follow-up studies include trauma severity, lack of hobbies, acute hyperarousal, subsequent traumatic events, job dissatisfaction, brooding over work, and lack of social support outside of work at 12 months posttrauma [Carlier et al., 1997]. The relationship between helplessness or horror responses, fear, and dissociation has been reported to be partially mediated by panic symptoms in police officers [Fikretoglu et al., 2007]. This supports the theory that acute fear responses, similar to numbing, may increase levels of PTSD [Benedek et al., 2007]. Preexisting dysfunctional factors, such as personality style and trait dissociation [Hodgins et al., 2001] have also been shown to be risk factors, as well as length of work assignment, uncertainty about help given to victims [Brauchle, 2006]. Inslicht et al. [2010] report that family history of depression and anxiety predict increased PTSD symptoms. In the present study a small but positive significant correlation was obtained between the start date of work at the WTC with Wave 2 PCL scores for men, but for women this relationship had twice the magnitude. Prior research has also recognized longer duration of work around the WTC, earlier start date, performing tasks different from those in one's general occupation, severity of initial anger, and not having had pre-disaster training as additional risk factors in the development of PTSD symptoms [Perrin et al., 2007; Farfel et al., 2008; Jayasinghe et al., 2008; Brackbill et al., 2009b].

The number of "days at work at the WTC" was not a significant predictor of PTSD symptoms at the time of the W2 survey. This is consistent with a study of PTSD among rape victims where duration of exposure had a small but significant clinical effect in the immediate time frame after trauma, but longer term adjustment was not influenced by this objective index of stressor magnitude [Kaysen et al., 2010]. In contrast, a study of Vietnam veterans found a significant relationship between the duration of combat exposure and prevalence and duration of PTSD symptoms [Buydens-Branchey et al., 1990].

\section{Mental Health Diagnoses}

Having a diagnosis of PTSD, anxiety disorder, or depression from a medical or mental health provider was related to higher Wave 2 PCL scores for both men and women. PCL scores were higher for those with a more recent diagnosis (between $9 / 11$ and Wave 1 or between Waves 1 and 2) than those who received their diagnosis before 9/11. Seeing a mental health professional or taking psychiatric medication was related to higher PCL scores. 
More women than men had diagnoses of anxiety, depression, or PTSD, were seeing a mental health professional, or were taking psychiatric medications. Receiving mental health care (including psychiatric medications) may have contributed to some of the police women's relative improvement in PTSD. Lilly et al. [2009] suggest that women tend to experience traumatic events with more intense emotionality than men. However, it has also been postulated that women who choose police work, a historically masculine occupational role, may be emotionally more similar to men [Lilly et al., 2009], but the results of the Waves 1 and 2 studies do not support this interpretation.

The magnitude of the 9/11 traumatic event, along with the fact that PTSD and co-morbid depression and anxiety can develop after a temporal delay of up to 6 years following a life-threatening event emphasize the need for a longitudinal approach to monitoring multiple adverse mental health effects following 9/11. Although averted, 14 new terrorism plots have been new and ongoing threats in NYC since 9/11. These plots activated NYPD's emergency response readiness and may redintegrate the police officers' prior PSTSD/stress reaction which might serve to maintain and possibly increase their prevalence of PTSD.

\section{Comparison With Other Follow-Up Studies of PTSD Among Police Following Disasters}

There is a scarcity of follow-up studies of PTSD in police populations. Type of disaster has been shown to be associated with the longevity of psychiatric reactions. Brauchle [2006] investigated the relationship between incidence- and reaction-related variables to predict acute and PTSD in rescue workers (police included) after the natural disaster of Kaprun in Austria in 2000. A fire occurred in an ascending railway car inside a tunnel which claimed the lives of 155 people. After 6 weeks, $25.7 \%$ of police responders experienced acute stress symptoms. At 6 months after the disaster, $6.3 \%$ of all rescue workers continued to report having some PTSD symptoms. A fire inside a tunnel might be less traumatic over time, with few visual reminders of the trauma, than the terrorist attack which destroyed the WTC towers.

\section{Strengths}

A strength of this report is our ability to apply DSMIV criteria for PTSD to this unique sample. Unfortunately, direct comparison of PTSD prevalence between firefighters and police who responded to $9 / 11$ cannot be made because the Berninger et al. [2010a, b] study did not use the standard PCL scoring.

The group of police being studied here at Wave 2 represents a very large sample size. This longitudinal study of police who responded to the worst terrorist attack on US soil contributes valuable knowledge on the longevity of mental health effects of this attack. It is relatively recent that non-white ethnic groups and women have been added to the police force but there is limited data on differences in PTSD among those subgroups.

Police in both the "Resilient" and "Recovered" groups are equally as important for further study as those in the "Chronic" and "Delayed" groups in shaping future prevention and treatment programs. Having this type of longitudinal data on police exposed to one of the most severe disasters is rare and presents a unique opportunity for further study.

\section{Limitations}

A limitation in our study is the lack of highly sensitive information of other potential risk factors for PTSD, such as additional traumatic events between the Waves 1 and 2 assessments, family history of mental illness, depression, and anxiety. Traumatic events between Waves 1 and 2 were not asked but this information is included in the WTCHR Wave 3 survey that is currently being carried out.

The significant demographic differences between the responders and non-responders to Wave 2 survey may have contributed to the differences observed in the PCL scores at Wave 2, despite adjusting for these factors in the analyses, Wave 2 survey non-responders had: proportionally more African-Amercans, lower income, fewer years of education, and more were unmarried and younger than Wave 2 responders. The greater non-response of lower income workers at Wave 2 and the association of lower income with greater PTSD suggest that this differential nonresponse by those with lower income might underestimate PTSD at Wave 2.

Another limitation in this type of research is the use of a self-administered screening instrument (PCL) rather than a clinical diagnosis by a psychiatric practitioner. Although the DSM-IV criteria appears on the surface more restrictive than the 44 PCL cut-off, the prevalence of those meeting DSM-IV criteria is higher (see Table IV) because only PCL items rated "moderate" or above are used for positive "PTSD" endorsement.

The police likely represent a unique culture compared to area residents in their reluctance to reveal and self-disclose due to fears of job consequences which may result in losing the privilege of carrying a weapon [Dowling et al., 2006]. This may also have compromised their willingness to enter treatment programs for PTSD.

The different survey modes used within each survey as well as between survey waves present an additional limitation to the findings of the study. Those who responded to the study by mail or web had higher average 
Wave 2 PCL scores and a greater increase in PCL scores over time than those responding by phone. These differences could reflect the methodological effects each of the modes has on self-report. The more anonymous mode of responding through web or mail may have permitted responders to self-disclose more candidly. Alternatively, rather than mode-dependent differences in willingness to self-disclose, the observed differences in PCL scores could reflect respondent characteristics associated with choosing one response mode over the other. Temporal factors, such as the large-scale public education campaigns normalizing mental health reactions to $9 / 11$, and availability of mental health evaluation and treatment resources that accelerated between 2004-2007 may also have played a role in encouraging police to increase their self-disclosure over time.

Although much has been written about WTC attack and PTSD, the police have not been compared to other first responder groups such as firefighters and other early responders, with the exception of the study by Perrin et al. [2007]. More in-depth comparisons could lead to a better understanding of the impact of the different approaches in each of these departments.

Prior sexual abuse, generally more prevalent among women than among men, was also not asked. No information on the demographic characteristics of the entire NYPD or other employers of other police who did not join the WTCHR was available. This may limit generalizability of these findings to the entire NYPD or other police departments.

\section{CONCLUSIONS}

It is notable that, contrary to expectations, the prevalence of probable PTSD in police registrants increased over time. The 9/11 event was of a magnitude never previously experienced on US soil and resulted in greater levels of PTSD and longer duration of this illness in the police first responders. It cannot be determined at this time whether the police registrants' increased prevalence of probable PTSD was also impacted by other traumatic events between the Waves 1 and 2 assessments, the work climate, or the type of work performed after the attack or other unknown factors. The results of this study showing an apparent lack of significant overall symptomatic improvement suggest that policies aimed at prevention and more effective treatment programs are recommended to prevent and ameliorate at least some of these adverse mental health effects. Addressing risk factors for PTSD in police within such treatment programs may increase their functional capacity in the aftermath of future terrorist attacks. Police will always be among the first responders at the scene of such disasters and institution of further preventive strategies is highly desirable.

\section{ACKNOWLEDGMENTS}

We thank the WTCHR police agency enrollees who responded for this follow-up of the 9/11/01. We also thank our colleagues Dr. Robert Brackbill, Dr. Mark Farfel, and Dr. Margaret Millstone from the WTCHR for reviewing the manuscript and providing helpful assistance. We acknowledge the support in part by Grant/Cooperative Agreement \# U50/ATU272750 from the ATSDR/CDC to the New York City DOHMH and the funding in part by Grant number 1U50OH009739-1 from the National Institute for Occupational Safety and Health (NIOHS/CDC). The contents of this manuscript are solely the responsibility of the authors and do not necessarily represent the official views of ATSDR/CDC, NIOSH/CDC, and The New York City DOHMH.

\section{REFERENCES}

Adams R, Boscarino J. 2006. Predictors of PTSD and delayed PTSD after disaster: The impact of exposure and psychosocial resources. J Nerv Ment Dis 194:485-493.

Adams R, Boscarino J, Galea S. 2006. Alcohol use, mental health status and psychological well-being 2 years after the World Trade Center attacks in New York City. Am J Drug Alcohol Abuse 32: 203-224.

American Psychiatric Association. 1994. Diagnostic criteria for DSM-IV. Washington, DC: American Psychiatric Association.

Benedek D, Fullerton C, Ursano R. 2007. First responders: Mental health consequences of natural and human-made disasters for public health and public safety workers. Annu Rev Public Health 28: 55-68.

Berninger A, Webber M, Cohen I, Gustave J, Lee R, Niles J, Chiu S, Zieg-Owens R, Soo J, Kelly K, Prezant D. 2010a. Trends of elevated PTSD risk in firefighters exposed to the World Trade Center disaster: 2001-2005. Public Health Rep 125:556-566.

Berninger A, Webber M, Niles J, Gustave J, Lee R, Cohen H, Kelly K, Corrigan M, Prezant D. 2010b. Longitudinal study of probable post-traumatic stress disorder in firefighters exposed to the World Trade Center disaster. Am J Ind Med 53(12):1177-1185.

Bonanno GA. 2004. Loss, trauma, and human resilience: Have we underestimated the human capacity to thrive after extremely aversive events? Am Psychol 59(1):20-28.

Bonanno GA, Rennicke C, Dekel S. 2005. Self-enhancement among high exposure survivors of the September 11th terrorist attack: Resilience or social maladjustment? J Pers Soc Psychol 88: 984-998.

Bonanno GA, Galea S, Bucciarelli A, Vlahov D. 2006. Psychological resilience after disaster: New York City in the aftermath of September 11th terrorist attack. Psychol Sci 17:181-186.

Bonanno GA, Brewin CR, Kaniasty K, La Greca AM. 2010. Weighing the costs of disaster: Consequences, risks, and resilience in individuals, families, and communities. Psychol Sci 11(1):1-49.

Bowler R, Han H, Gocheva V, Nakagawa S, Alper H, DiGrande L, Cone J. 2010. Gender differences in probable posttraumatic stress disorder among police responders to the 2001 World Trade Center terrorist attack. Am J Ind Med 53(12):1186-1196. 
Brackbill R, Hadler J, Digrande L. 2009a. Asthma and posttraumatic stress symptoms 5 to 6 years following exposure to the WTC terrorist attack. JAMA 302(5):502-516.

Brackbill R, Hadler J, DiGrande L, Ekenga C, Farfel M, Friedman S, Perlman S, Stellman S, Walker D, Wu D, Yu S, Thorpe L. 2009b. Asthma and posttraumatic stress symptoms 5 to 6 years following exposure to the World Trade Center terrorist attack. JAMA 302(5): $502-516$.

Brauchle G. 2006. Incidence- and reaction-related predictors of the acute and posttraumatic stress disorder in disaster workers. [In German.] Z Psychosom Med Psychother 52(1):52-62.

Buydens-Branchey L, Noumair D, Branchey M. 1990. Duration and intensity of combat exposure in posttraumatic stress disorder in Vietnam veterans. J Nerv Ment Dis 178(9):582-587.

Carlier I, Lamberts R, Gersons B. 1997. Risk factors for posttraumatic stress symptomatology in police officers: A prospective analysis. J Nerv Ment Dis 185(8):498-506.

CDC (Centers for Control Disease Prevention). 2002a. Impact of September 11 attacks on workers in the vicinity of the World Trade Center-New York City. MMWR Morb Mortal Wkly Rep 51:8-10.

CDC (Centers for Disease Control and Prevention). 2002b. Injuries and illnesses among New York City fire department rescue workers after responding to the World Trade Center attacks. MMWR Morb Mortal Wkly Rep 51:1-5.

City of New York Bureau of Vital Statistics. 2003. Summary of vital statistics 2002. New York City: Department of Health and Mental Hygiene.

Department of Health and Human Services. Mental health: A report of the Surgeon General (Table 2-6). http://www.surgeongeneral. gov/library/mentalhealth/chapter2/sec2_1.html\#table2_6. Accessed March 11, 2010.

Dowling FG, Moynihan G, Genet B, Lewis J. 2006. A peer-based assistance program for officers with the New York City Police Department: Report of the effects of Sept. 11, 2001. Am J Psychiatry 163(1):151-153.

Farfel M, DiGrande L, Brackbill R, Prann A, Cone J, Friedman S, Walker D, Pezeshki G, Thomas P, Galea S, Williamson D, Frieden T, Thrope L. 2008. An overview of 9/11 experiences and respiratory and mental health conditions among World Trade Center health registry enrollees. J Urban Health 85(6):880-909.

Fikretoglu D, Brunet A, Best SR, Metzler TJ, Delucchi K, Weiss DS, Fagan J, Liberman A, Marmar CR. 2007. Peritraumatic fear, helplessness and horror and peritraumatic dissociation: Do physical and cognitive symptoms of panic mediate the relationship between the two? Behav Res Ther 45(1):39-47.

Galea S, Ahern J, Resnick H, Kilpatrick D, Bucuvalas MJ, Gold J, Vlahov D. 2002. Psychosocial sequelae of the September 11th terrorist attacks in New York City. N Engl J Med 346:982-987.

Galea S, Vlahov D, Tracy M, Hoover D, Resnick H, Kilpatrick D. 2004. Hispanic ethnicity and post-traumatic stress disorder after a disaster: Evidence from a general population survey after September 11, 2001. Ann Epidemiol 14(8):520-531.

Galea S, Ahern J, Tracy M, Hubbard A, Cerda M, Goldmann E, Vlahov D. 2008. Longitudinal determinants of posttraumatic stress disorder in a population-based cohort study. Epidemiology 19(1): $47-54$.

Hodgins G, Creamer M, Bell R. 2001. Risk factors for posttraumatic reactions in police officers: A longitudinal study. J Nerv Ment Dis 189(8):541-547.

Inslicht SS, McCaslin SE, Metzler TJ, Henn-Haase C, Hart SM, Neylan TC, Marmar C. 2010. Family psychiatric history, peritraumatic reactivity, and posttraumatic stress symptoms: A prospective study of police. J Psychiatr Res 44:22-31.

Jayasinghe N, Giosan C, Evans S, Spielman L, Difede J. 2008. Anger and Posttraumatic Stress Disorder in disaster relief workers exposed to the September 11, 2001 World Trade Center disaster. J Nerv Ment Dis 196(11):844-846.

Katz CL, Levin S, Herbert R, Munro S, Pandya A, Smith R. 2009. Psychiatric symptoms in ground zero ironworkers in the aftermath of 9/11: Prevalence and predictors. Psychiatr Bull 33:49-52.

Kaysen D, Rosen G, Bowman M, Resick PA. 2010. Duration of exposure and the dose-response model of PTSD. J Interpers Violence 25(1):63-74.

Kessler RC, Andrews G, Colpe LJ, Hiripi EE, Mroczek DK, Normand SL, Walters EE, Zaslavsky AM. 2002. Short screening scales to monitor population prevalences and trends in non-specific psychological distress. Psychol Med 32(6):959-976.

Lawyer SR, Resnick HS, Galea S, Ahern J, Kilpatrick DG, Vlahov D. 2006. Predictors of peritraumatic reactions and PTSD following the September 11th terrorist attacks. Psychiatry 69(2):130-141.

Levenson RL Jr, Acosta JK. 2001. Observations from Ground Zero at the World Trade Center in New York City. Part I. Int J Emerg Ment Health 3(4):241-244.

Lilly M, Pole N, Best S, Metzler T, Marmar C. 2009. Gender and PTSD: What can we learn from female police officers? J Anxiety Disord 23:767-774.

Norris FH, Friedman MJ, Watson PA, Byrne CM, Diaz E, Kaniasty K. 2002. 60,000 disaster victims speak: Part I. An empirical review of the empirical literature, 1981-2001. Psychiatry 65(3):207-239.

Perlman SE, Friedman S, Galea S, Nair HP, Eros-Sarnyai M, Stellman SD, Hon J, Greene CM. 2011. Short-term and medium-term health effects of 9/11. Lancet 378:925-934.

Perrin M, DiGrande L, Wheeler K, Thorpe L, Farfel M, Brackbill R. 2007. Differences in PTSD prevalence and associated risk factors among World Trade Center disaster rescue and recovery workers. Am J Psychiatry 164(9):1385-1394.

Pole N, Best SR, Weiss DS, Metzler T, Liberman AM, Fagan J, Marmar CR. 2001. Effects of gender and ethnicity on duty-related posttraumatic stress symptoms among urban police officers. J Nerv Ment Dis 189:442-448.

SAS Institute, Inc. 2008. SAS/STAT software. 9.2. Cary, NC: SAS Institute, Inc.

Schlenger WE, Caddell JM, Ebert L, Jordan BK, Rourke KM, Wilson D, Thalji L, Dennis JM, Fairbank JA, Kulka RA. 2002. Psychological reactions to terrorist attacks: Findings from the National Study of Americans' Reactions to September 11. JAMA 288(5):581588 .

Silver RC, Holman EA, McIntosh DN, Poulin M, Gil-Rivas V. 2002. Nationwide longitudinal study of psychological responses to September 11. JAMA 288(10):1235-1244.

SPSS, Inc. 2009. PASW statistics 18. Chicago, IL: SPSS, Inc.

Stellman JM, Smith RP, Katz CL, Sharma V, Charney DS, Herbert R, Moline J, Luft BJ, Markowitz S, Udasin I, Harrison D, Baron S, Landrigan PJ, Levin SM, Southwick S. 2008. Enduring mental health morbidity and social function impairment in World Trade Center rescue, recovery, and cleanup workers: The psychological dimension of an environmental health disaster. Environ Health Perspect 116(9): $1248-1253$

Tedeschi RG, Calhoun LG. 1995. Trauma and transformation: Growing in the aftermath of suffering. Thousand Oaks, CA: Sage Publications. 
U.S. Department Veterans of Affairs, National Center for PTSD. 2010. Traumatic effects of specific types of disasters. http:// www.ptsd.va.gov/professional/pages/traumatic-effects-disasters.asp. Accessed October 20, 2011.

Vlahov D, Galea S, Resnick H, Ahern J, Boscarino JA, Bucuvalas M, Gold J, Kilpatrick D. 2002. Increased use of cigarettes, alcohol, and marijuana among Manhattan, New York, residents after the
September 11th terrorist attacks. Am J Epidemiol 155(11):988996.

Weissman M, Neria Y, Das A, Feder A, Blanco C, Lantigua R, Shea S, Gross R, Gameroff M, Pilowsky D, Olfson M. 2005. Gender differences in posttraumatic stress disorder among primary care patients after the World Trade Center attack of September 11, 2001. Gend Med 2(2):76-87. 